\title{
A NEW REVOLUTION: DATA REVOLUTION (THE FIRST STEPS OF MOLDOVA)
}

\author{
Igor Cojocaru $^{1}$, Ion Cosuleanu ${ }^{2}$, Anastasia Stefanita ${ }^{3}$, \\ Irina Cojocaru ${ }^{4}$ and Costel Todor ${ }^{5}$
}

\begin{abstract}
The new Agenda 2030 for sustainable development universally adopted by the UN in 2015 with the 17 Sustainable Development Goals (SDGs) aims to fight poverty, inequality and climate change. It requires collective action at all levels, more evidence-based development policy-making, better availability of quality data and statistics, and strengthened accountability of development stakeholders, requiring in other words a "Data Revolution for Sustainable Development". At the moment, Republic of Moldova is in process of nationalizing the SDGs with the support of UNDP.
\end{abstract}

Since data revolution represents the process of monitoring the progress and response to SDG challenges, Moldova was part of a global initiative undertaken in 7 different countries, for mapping and inventory of the data system in each country, required for measuring the sustainable development progress. Its overall objective was to assess the availability of data and institutional modernization capacity needed to implement the post-2015 development agenda. The paper presents the steps undertaken in Moldova for mapping the situation for future localization/adaptation of SDGs to ensure their monitoring in order to achieve the post-2015 Agenda using ICT tools.

\section{Introduction}

\subsection{Global context: Need for Data Revolution}

The new global post-2015 Development Agenda „Transforming our world: the 2030 Agenda for Sustainable Development" was adopted at the 70th session of the United Nations (UN) General Assembly in September 2015 by 193 countries. The Agenda includes a new set of 17 global development goals to transform the world - the Sustainable Development Goals (SDGs) and 169 targets [13].

The UN High-Level Panel of Eminent Persons on the post-2015 agenda has called for a "data revolution for sustainable development, with a new international initiative to improve the quality of statistics and information available to citizens" [1]. Data are the lifeblood of decision-making and the raw material for accountability. Without high-quality data providing the right information on the right things at the right time; designing, monitoring and evaluating effective policies becomes almost impossible [2].

As stated in the National Report of Moldova [10], data revolution may be defined as the analysis and decision-making process for the sustainable development of the society and the world, by using the existing data sources, as well as attracting other data sources and promoting free access to these sources. Data Revolution can be carried out by stakeholders who have responsibilities with regard

\footnotetext{
${ }^{1}$ Information Society Development Institute, Chisinau, Moldova, igor.cojocaru@idsi.md

${ }^{2}$ Information Society Development Institute, Chisinau, Moldova, ion.cosuleanu@idsi.md

${ }^{3}$ Information Society Development Institute, Chisinau, Moldova, anastasia.stefanita@idsi.md

${ }^{4}$ Information Society Development Institute, Chisinau, Moldova, irina.cojocaru@idsi.md

${ }^{5}$ CIVICUS Management \& Development Company, Bucharest, Romania, costel.todor@civicus-mdc.ro
} 
to data (called "data communities") and which interact with each other through various institutions, with effective enforcement of laws and policy framework and the use of innovative technologies, thus creating a "data ecosystem" [11]. To support a coordinated and coherent process concerning the implementation of the SDGs worldwide, a framework for monitoring and evaluating the progress, having established targets and indicators for each objective has been developed. The monitoring process requires commitment from the authorities, respectively from the community in general, and the existing capacity to collect process and use the data by each country [5].

New technologies and new platforms for gathering and bringing data together, new stakeholder partnerships and new ways of using data by analysts, policy makers, businesses and citizens are the main characteristics of data revolution [6]. These new instruments and approaches are built on ICTbased tools that serve as an important platform for implementation of SDGs and for monitoring progress toward their achievement [7].

\subsection{Country context: Need for data ecosystem mapping and applied methodology}

The Post-2015 Agenda believes that the support and expertise from academia, private sector and civil society, encouraging innovation as an approach and/or instrument in producing statistical data is a critical element for strengthening national statistical offices for the revolutionary use of data and exploring new technologies and innovative approaches [3]. Beside this fact, the main goal of using data in an extensive way is the evidence-base decision making process for the development of society. In this context, it is considered useful and necessary for each UN member country to conduct a mapping of the data ecosystem describing the current situation and submitting a needs analysis for the achievement of a data revolution, as an essential element in the decision-making process [12].

UNDP Moldova has launched an activity, as part of a global initiative undertaken in 7 different countries, for mapping/inventory of the data system in the country, required for measuring the sustainable development progress. Its overall objective was to assess the availability of data in an inclusive and participatory manner and institutional modernization capacity needed to implement the Post-2015 Agenda in the Republic of Moldova, the structure and stakeholders' involvement, the use and importance of data and the mechanisms employed in the decision-making process [8].

The chosen methodology for the mapping was oriented towards identifying ways of obtaining statistical data for purposes of needs assessments and towards raising awareness of the responsibilities carried by stakeholders involved both in sustainable development and developing evidence-based policies, or in other words, in supporting "Data Revolution for Sustainable Development". The "desk review" method was used for assessing the SDGs preliminary applicability / feasibility for Moldova by examining and analysing the availability of indicators assigned to each SDG in the national statistical system.

Further undertaken activities (workshops, analysis by questionnaires) aimed at capturing the perspective, experiences and challenges of these categories of institutions/stakeholders regarding data use or production and identifying synergies and opportunities for collaboration among them. 
The analysis was conducted from the perspective of:

a) availability and functioning of the normative framework on the production of official statistics, data processing and data use in decision making;

b) availability \& operability of the information and communications technology (ICT) tools and systems;

c) observing and identifying the capacity in terms of human resources involved in producing the data and the need for training for data use;

d) the availability of organizational and financial resources for the data production process; and

e) identifying and emphasizing innovative ideas and solutions suggested by the data communities for monitoring and evaluating the implementation of Sustainable Development Goals.

The mapping results are reflected in the National Report: Data Revolution Ecosystem Mapping in the Republic of Moldova [10].

\section{Mapping Process Results}

The mapping of data ecosystem started with the desk review of national development strategies and plans, progress reports on their implementation, as well as monitoring and evaluation activities in collaboration with civil society, academia, private sector and citizens. The overview on the state of the art of data ecosystems was undertaken in line with international best practices on Data Revolution.

A preliminary inventory of statistical indicators available at the national level, produced by the National Bureau of Statistics (NBS) and other data producers and their comparison with the 230 SDG indicators published by the UN Economic and Social Council was undertaken. Along with the identification of the authority responsible for data collection for each indicator, the data source for both available and missing indicators has been identified, as well as reconfirming or identifying the relevant stakeholders that could participate in monitoring the SDGs implementation.

At first glance, the analysed strategic documents show that Moldova in general, has anchored the long-term development objectives (see "Moldova 2020" [9]) to the Millennium Development Goals (MDGs). This approach allowed a certain correlation of monitoring and evaluation, by defining the indicators and the reporting process of progress, on the one hand with the basic document "Moldova 2020", and the subsequent sectoral strategies, on the other hand.

The mapping process involved the preliminary analysis of the availability/applicability in the national strategic documents of SDG targets (169 targets) and indicators (230 indicators). Compared to national specificities, it was found that all SDGs in principle are applicable for Moldova. When referring to SDGs indicators, 211 of the total of 230 SDG indicators were considered relevant at this stage. These relevant indicators were identified per the following groups: Social, Economic, and Civil Rights \& Governance. The evaluation of data availability per areas and stakeholders, enables observing the distribution by types of data producers and owners, and also from the perspective of the monitoring and evaluation process. Out of 211 SDG indicators identified as applicable to Moldova, most are found in the Social area (69 indicators) and the Civil 
Rights \& Governance area (56 indicators). Moreover, 70 indicators (33\%) are fully available and 141 indicators $(67 \%)$ are considered partially available or missing. However, referring to the availability of indicators, it was found that most data collection efforts should be directed towards areas of Energy \& Environment and Civil Rights \& Governance (Table 1).

\begin{tabular}{|l|c|c|c|}
\hline \multicolumn{1}{|c|}{ Domain/Indicators } & $\begin{array}{c}\text { SDGs considered } \\
\text { indicators }\end{array}$ & $\begin{array}{c}\text { Integrally } \\
\text { available } \\
\text { indicators }\end{array}$ & $\begin{array}{c}\text { Partially or totally } \\
\text { missing indicators }\end{array}$ \\
\hline Social & 69 & 32 & 37 \\
\hline Economic & 39 & 16 & 23 \\
\hline Energy \& Environment & 47 & 10 & 39 \\
\hline Civil Rights \& Governance & 56 & 12 & 44 \\
\hline Total & $\mathbf{2 1 1}$ & $\mathbf{7 0}$ & $\mathbf{1 4 1}$ \\
\hline
\end{tabular}

Table 1: The availability of indicators by area [10]

The analysis revealed a relatively balanced distribution of indicators in the 4 considered areas and the inventory enabled the identification of indicators by category of data producers in the national institutions. The analysis was further expanded to resources needed for the data revolution: legal framework and procedures, human resources and skills, ICT infrastructure and financial resources. An important component of mapping SDGs is assessing the position of central public authorities with reference to the data ecosystem. In this context, for each indicator were identified both the institution responsible for its collection and production, and those responsible for monitoring and evaluating the strategic framework with reference to specific indicators.

Overall, the data community can be divided into 3 distinct categories: data producers, data owners and data users. The mandate and commitment to data of each data community participant, including visions and requirements are defined according to these categories. However, some entities which have responsibilities related to data may be found simultaneously in several categories, which increases their role in the national data ecosystem.

The mapping shows that in all SDG incumbent indicators, relevant for Moldova, the leading producer of indicators is the NBS, which is responsible for producing 46 indicators, of which 19 in the economic area, 19 in the social area, 5 in the environmental and energy area and 3 in the rights and governance area. It is followed by the National Centre of the Ministry of Health, which is responsible for producing 14 SDG incumbent indicators. The leadership on the analysis and monitoring of SDG related indicators falls under the Ministry of Health, which has responsibility under 30 indicators, of which 25 indicators in the social area, followed by the Ministry of Labour, Social Protection and Family (28 indicators) and the Ministry of Economy ( 27 indicators).

Analysis of data availability by areas and stakeholders makes it obvious that a large number of SDGs indicators (150) are in the possession of data holders or the institutions responsible for monitoring and evaluation of SDGs (148), as compared to indicators in the possession of data producers (90), which should eventually lead to a distribution of tasks and efficient use of resources in the process of SDGs implementation, monitoring and reporting.

Considered indicators for all areas covered by SDGs can be determined and measured in Moldova by using all known sources, including: selective household research/ population studies; population and housing census, agricultural census; administrative data (registries, databases, internal records for a 
particular purpose); data on civil status, vitality statistics (births, deaths, marriages, divorces, etc.); geospatial data (data on geographical location, natural or constructed features of objects, their limits in a given area). The availability of these sources and the statisticians' experience in their use can be considered important advantages for building the administrative capacity to develop official statistics. With the assumption of SDGs, Moldova is to make major efforts in filling the missing indicators, as well as in disaggregation of those considered relevant at the national level. Another important aspect is the need to delineate, at the stage of nationalization, the role of each institution responsible for producing and reporting SDG indicators. The efficient resource channelling should consider delegating some responsibilities specific to data processes to a single institution, so as to avoid the duplication of certain activities and reduce the reporting burden.

The use of data in decision making still remains a great challenge, and in this sense one of the major issues is data quality, which refers not only to accuracy, but also to the availability, completeness, relevance, validity and actuality. In terms of ICT infrastructure, especially in ensuring access and connectivity, Moldova is in principle ready for monitoring SDG indicators, thus being able to carry a data revolution. Along with the decrease of urban-rural, regional-central existing gaps, the process will become comprehensive and effective.

Most sectoral strategies and plans developed by the government and public authorities addressed the country targets generally related to MDGs. However, even though the strategies have a monitoring and evaluation framework that includes the result indicators, they are defined at insufficient level related to those suggested for SDGs. It would be necessary in the immediate future to correlate the national strategies' targets with SDGs and to review the monitoring and evaluation framework, by harmonising and adapting the proposed SDG indicators as much as possible for local situation, but also ensuring the openness of public authorities for partnerships with stakeholders in the collection, processing (academia, private sector, local government, civil society) and involvement in public policy adjustments for the SDGs performance indicators. Among the evaluated strategies "The Republic of Moldova Innovation Strategy for 2013-2020" can be highlighted as an example of monitoring and evaluation framework with clear baseline and impact indicators, intermediate and final indicators, mostly defined according to international organizations' practices (e.g. the World Bank).

The main stakeholders identified for the SDGs process include the State Chancellery, National Bureau of Statistics, Ministries and public agencies, E-Government Centre, local public administration, academia, civil society, international donors, private sector representatives. The needs analysis of data communities and the assessment of the state of play regarding the availability of data for monitoring the implementation of SDGs was conducted by applying / delivering and filling in a questionnaire dedicated to target respondents (in the identified data communities).

The consultation process has been backed up at State Chancellery level, which officially advised on SDGs, mapping process and data revolution and guided all public authorities in the country in filling in the questionnaire, whether on-line or off-line. Questionnaires were filled in over 15 days by 118 organizations/institutions. Based on the survey results, the availability of information for the public on data collection and dissemination conditions requires more concerted efforts. Due to the legislation on personal data protection that is in force, data producers and owners started paying greater attention to issues related to data privacy, personal data processing, informing the public about these issues etc. However, more sustained efforts are needed in this regard, because, as the data of the study show, only over 50 percent of data producers and owners make the information on the manner and conditions of data collection (52\%) and dissemination (57\%) available for the public. In the same 
context, at present, some public institutions use alternatives (innovative methods) for data collection, analysis and presentation - such as specific software, automated registers (e.g. The State Register of Voters is interconnected with the Register of Population), information systems (e.g. Civil Service population records; MICT - population documentation system etc.) [10].

A series of 5 workshops (attended by 188 people) have been conducted for consultations on Data Ecosystem Mapping. These workshops were attended by representatives of data communities distributed for consultation purposes by large thematic areas, as a result of SDG grouping under integrated implementation approach: economic; social; energy \& environment; civil rights \& governance. The workshops' programme included information about SDG and their targets, a description of the areas and the situation regarding SDG indicators by area versus the availability of indicators at the national level and data holders, as well as data sources to secure the requested indicators, the presentation on the operation of the Open data public system, managed by eGovernment Centre [14].

\section{The data ecosystem model for Moldova}

A model of the data ecosystem considered functional for Moldova would entail using data flows in decision-making by stakeholders, to secure the strategic priorities correlated with SDG targets and their implementation through a committed and engaging, responsible, transparent and monitored process with civic participation (Figure 1). The functioning model of the data ecosystem for the informed decisionmaking employing the data revolution, highlights the interaction of the stakeholders involved in decision-making (government, civil society and academia, the private sector /entrepreneurial environment, together with international partner organizations) and decision-driven resources (institutions, legal framework, policy, human resources, infrastructure and ICT, financial resources), using data and information production (collection, processing, access and data exchange, dissemination, analysis and use of data) for monitoring and evaluation of indicators, resulting throughout action plans implementation of strategic documents, through a transparent process and in partnership with the civil society, to adjust the national strategic objectives by reference to the SDG targets.

The central component of the data ecosystem is the process of transforming data into evidence / tools to support public decisions. The robustness of the transformation process, the knowledge and its application by all stakeholders will provide a set of consistent data, coherent and useful for the decision-making process. From this perspective, the proper operation of the data ecosystem entails an analysis and evaluation of processes for collecting, processing, access and data exchange (dissemination), analysis and use of data for public policy and the use of innovative approaches and solutions to provide the necessary data and to meet the challenges, arising from the data revolution. Today, data collection can be an activity carried out by any actor involved in the decision-making process, respectively by the government and public agencies, civil society, academia and the private sector, for various purposes of private or public interest and by using diverse methods and technologies. Moldova data ecosystem uses all data sources and has access to advanced technology to respond to requests for data collection, necessary for purposes of processing and dissemination. 


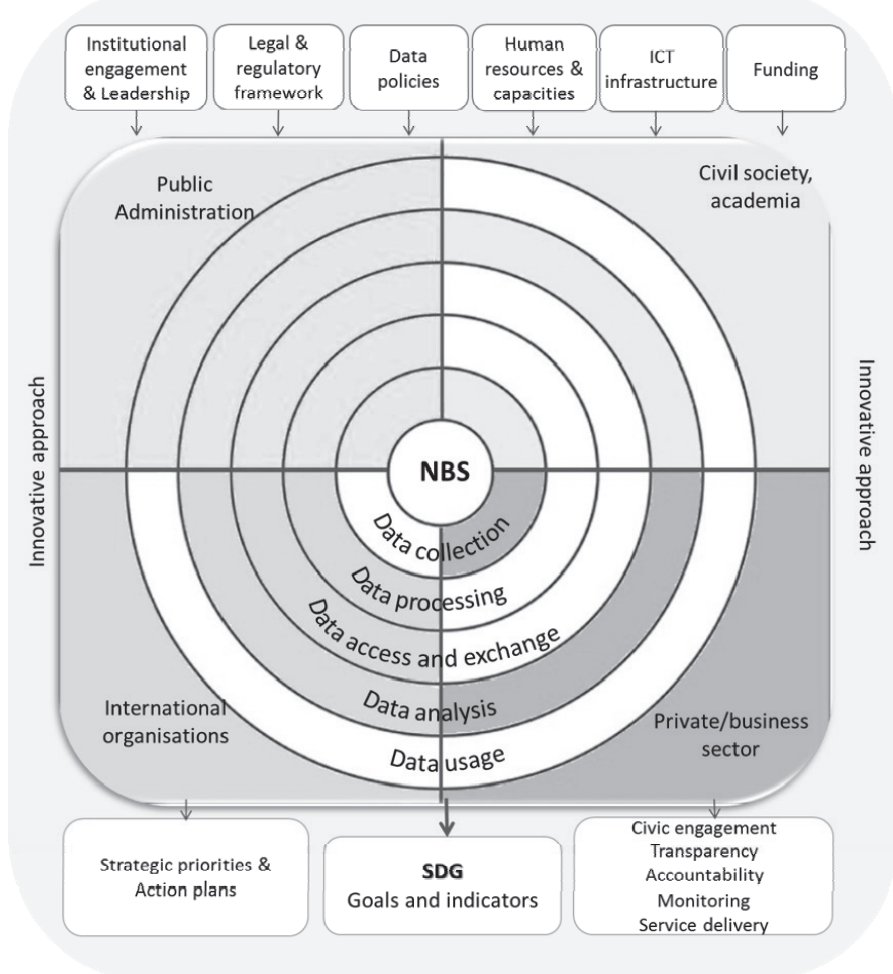

Figure 1: Data ecosystem model for Moldova in SDG context [10]

An efficient use of results of data collection and processing implies the application of quality control standards, the use of statistical and ICT capabilities for processing and archiving and the application of methods and standardized formats for data, useful to end beneficiaries in targeted analysis. Data production is not, and cannot be an end in itself, without ensuring the access and data exchange - data dissemination - between stakeholders, and ultimately, without the use of data in the decision making process. Dissemination should require availability of data in open and reusable formats for the benefit of citizens and other stakeholders, so that the ultimate usefulness of data would not be altered. The substantiation and support of the decisions with arguments by all stakeholders implies a minimum activity for the analysis of data available in the ecosystem. Data analysis is performed via statistical tools by transforming data into useful information and evidence for policy evaluation. Using statistical tools and visualization techniques for data analysis, implies the existence of skilled personnel, certain applications and a communication infrastructure, financial resources and assigning tasks through operating regulations for the use of methodologies confirmed, eventually resulting in data products that are used in decision-making.

Data usage becomes the critical component in the decision making process within the ecosystem. Assessing the current situation regarding data use within the ecosystem will enable the development or strengthening of human resources, procedures and partnerships, so that data can be used to justify policies, monitor implementation and report progress, to empower citizens in holding the involved stakeholders, i.e. the public administration, accountable for decision-making and the results achieved using the resources allocated for the implemented actions. 
From the perspective of SDG implementation and reporting, distribution by institutions and groups of producers, owners and indicators' monitors, may result in a better allocation of tasks and responsibilities regarding reporting on the SDG implementation. Preliminary, it is useful to analyse and evaluate the means, resources and tools available for the stakeholders that can be used in data revolution. The current data is not sufficient to monitor the implementation of SDGs, therefore, in order to adjust the national policy and strategic priorities framework in line with SDG targets, a data revolution is needed. This entails an innovative approach to statistical processes, to increase the volume of data and the speed of data production, boosting the number of data producers, data dissemination and data mining.

\section{Next actions: SDGs targets and indicators localization}

The mapping of data ecosystem is just the precursor of the SDG localization for Moldova, and the stakeholders involved in the mapping process of mapping by means of questionnaires and/or participating in the workshops, can support the next steps in data revolution, in an assumed, coordinated process. The potential steps, grouped by several areas of intervention, are presented below.

\section{Institutionalization:}

- Develop a formal institutional framework for promotion of knowledge and SDG awareness at the national and local levels, accessible to all stakeholders and coordinated by the State Chancellery, on SDG targets and monitoring indicators;

- Review Government Decisions regulating the strategic planning and decision-making process, by introducing the SDG indicators, as recommended for monitoring and evaluating national strategies;

- Initiate a process of identification by the NBS, with the support of users and the Government, of the possible candidates for establishing innovation development partnerships in the field of statistics, based on their potential (private sector and academia, civil society);

- Motivate the producers and owners of alternative data sources from the private sector, civil society organizations by: establishing new partnerships, ICT assistance or financial support for production, accumulation or use of alternative data sources.

\section{Policies and standards:}

- Develop an Action Plan to revise the relevant national strategies, primarily Moldova 2020 strategy, to align it to SDG;

- $\quad$ Simulate in the framework of pilot projects, the policy impact assessment processes, by using SDG indicators and designing policies involving all stakeholders in the pilot areas (e.g. education, environment, economy, administration); 
- $\quad$ Secure private-public partnership mechanisms for commissioning statistics services to users;

- Adopt and implement NUTS in Moldova's national statistic system, for the compatibility with standards and promotion of European statistics in the framework of the public administration reform and the Territorial-administrative reform;

- Use traditional and alternative data sources to perform the impact analysis.

\section{Infrastructure and investments:}

- Financial incentives for partnerships between the private-public-academic sectors to enhance the use of local IT companies' capacity, for the implementation of innovative ways for collection, processing and effective analysis of existing data - automating the process of working with data (electronic chip, bar code, QR code, SMART GRID smart meters, etc.);

- Ensuring access to broadband in all rural areas, in the framework of the public administration reform at local level;

- Inventory of ICT infrastructure and IT applications within the national statistical system, to assess their ability to respond to the data revolution;

- Establish infrastructure investment programs, necessary for statistics in all ministries and public agencies and implement investment projects in ICT infrastructure in partnership with communications operators and the private sector.

\section{Data usage platform:}

- Approve a unique national monitoring and evaluation framework, correlated with SDG for Moldova, based on international best practices and evaluation frameworks with comprehensive libraries of definitions, metadata, taxonomies, metrics and implementation guides;

- Make data available in standardized and reusable formats, agreed upon with the NBS, using already operational instruments (e.g. open data portal);

- Increase the use of the Government interoperability platform and exclude the cases of delaying the connection of public institutions to this platform;

- Develop a national platform with indicators dashboard for monitoring the national strategies, including SDG, and opening it to the public for information and feedback.

\section{Promotion and training:}

- Organize workshops with stakeholders to agree on methods for the collection, production and analysis of data necessary for monitoring; annual conferences on SDG achievement;

- $\quad$ Fund a state research program regarding the Sustainable Development Goals; 
- $\quad$ Focus the applied research and development projects financed from public funds on topics. that contribute to achievement of SDGs and their related indicators;

- Organize competitions in promoting innovative solutions for the use of data from different sources and their integration, in case of their quality validation, in the official flows of data, used for monitoring and evaluation of public policies;

For a successful data revolution it is important that stakeholders are familiar with the list of recommendations issued under the aegis of the UN Secretary General "Data in support of the post2015 development agenda: Data revolution". All these actions must be promoted and discussed within the workshops on SDG localization and can be applied immediately, so the opportunity is left open for all stakeholders to participate in the implementation, by bringing ideas on actions' improvement, by defining partnerships based on actions, by commitment on contributing resources and by accountability regarding the results expected in the data revolution.

\section{Current actions}

Following the above mentioned activities, immediately after the National Conference that took place on June 15, 2016 [4], and where the National Report: "Data Revolution Ecosystem Mapping in the Republic of Moldova" was presented, the next actions have been launched. A series of seminars on SDG targets localization and consultations with stakeholders were organized under the coordination of State Chancellery and with UNDP support. The purpose of the current actions is to debate the SDG targets with public servants from the authorities directly involved in implementing, monitoring and evaluating the national strategies. The expected result was to identify which SDG targets are available for Moldova, based on the actual strategic provisions for each area. The discussions showed that several national and sectorial strategies should be revised, taking into account SDG targets and a balanced monitoring and evaluation scheme. The action plans of strategies and other documents should be updated with new actions and resources, in line with SDGs and UN requirements.

\section{Next steps}

The National Report defined some recommendations, addressing future developments to implement concrete measures, including those defined by the draft development strategy of the National Statistical System (NSS), which is the largest data ecosystem in Moldova. Therefore, inter alia, it is recommended:

- improving legal and operational frameworks of the NSS, to integrate specific services of the official statistics with those offered and provided by data communities and to ensure timely implementation of the newest IT tools;

- correlation, diversification and expansion of coverage areas of the official statistics, to include the priority fields from the national strategic objectives in the "Moldova 2020" strategy and the sectoral strategies (health, education, agriculture, environment, energy, justice, information technology, etc.) that are harmonized with SDGs;

- the need to meet the requirements of economic and financial environment, entrepreneurs, analysts, media and the public at large, to have relevant and timely statistics in various areas of public interest; 
- developing of statistical specialists pool in Moldova and supporting the statistical topics and curricula around universities and inside NSS;

- $\quad$ encouraging the culture of statistics towards a statistical literacy process for all stakeholders of decision making process.

\section{Conclusions}

Implementing the minimum measures listed above, Moldova could progress very fast on data revolution announced by UN Secretary general, H.E. Ban Ki-Moon [15] and will count on scope of „no one left behind”. The prerequisites are partialy set, the basic capabilities exists and can be developed further, and the benefits of data revolution could be reflected in a short time in the lifes of all citizens as part of decision making process based on evidencies. However, the announced by the Government Central Public Administration Reform should take into consideration the assumed by the country commitments to implement SDG and follow the recommended actions.

\section{References}

[1] A New Global Partnership: Eradicate Poverty and Transform Economies through Sustainable Development. The Report of the High-Level Panel of Eminent Persons on the Post-2015 Development Agenda. UN, May 2013.

[2] A World That Counts. Mobilizing the Data Revolution for Sustainable Development. Expert Advisory Group on a Data Revolution for Sustainable Development. UN, November 2014.

[3] Data for Development. An Action Plan to Finance the Data Revolution for Sustainable Development, Sustainable Development Solutions Network a Global Initiative for United Nations, Open Data Watch, July 2015.

[4] Data revolution: that's how Moldova will achieve the 2030 Development Agenda, $\mathrm{http}: / /$ idsi.md/national-conference-data-revolution-moldova accessed on 08.12.2016.

[5] HLPF Draft Summary, 2016, available at: https://sustainabledevelopment.un.org/content/ documents/10858SummaryPresident\%202016\%20HLPF\%20FINAL.pdf accessed on 27.10.2016.

[6] KINDORNAY, S., BHATTACHARYA D., HIGGINS, K.: Implementing Agenda 2030: Unpacking the Data Revolution at Country Level. Dhaka: Centre for Policy Dialogue (CPD), June 2016.

[7] MANOJ, M.: Big Data Governance Frameworks for "Data Revolution for Sustainable Development", available at: http://cis-india.org/internet-governance/blog/big-datagovernance-frameworks-for-data-revolution-for-sustainable-development, accessed on 23.10.2016.

[8] Moldova Data Revolution - country sustainable development, http://idsi.md/Moldova-DataRevolution-country-sustainable-development, accessed on 08.12.2016. 
[9] National Development Strategy: 7 solutions for economic growth and Poverty Reduction "Moldova 2020". Law no. 166 from 11.07.2012.

[10] National Report: Data Revolution Ecosystem Mapping in the Republic of Moldova, UNDP, CIVICUS Management and Development Company - CMD Company SRL, Information Society Development Institute, May 2016.

[11] Study: Monitoring the implementation of the Sustainable Development Goals - The role of the data revolution. European Parliament. Directorate-General for External Policies. Policy Department, July 2016.

[12] Sustainable Development Knowledge Platform, https://sustainabledevelopment.un.org accessed on 08.12.2016.

[13] Transforming our world: The 2030 Agenda for Sustainable Development A/RES/70/1. UN, October 2015.

[14] Workshops on Data Revolution: Moldova, 2016, http://idsi.md/ateliere-de-lucrucartografierea-datelor-in-Moldova, accessed on 08.12.2016.

[15] UN Secretary-General Antonio Guterres and the Sustainable Development Goals http://www.un.org/sustainabledevelopment/secretary-general/ 